\title{
2 \\ CONTROL Y EVALUACIÓN DE GESTIÓN Y RESULTADOS
}

\author{
Jorge Hintze ${ }^{1}$ \\ Director de TOP \\ (Tecnología para la Organización \\ Pública, Asociación Civil).
}

\section{RESUMEN}

El control y la evaluación son inherentes a las organizaciones e indispensables para su funcionamiento. Sin embargo, si bien forman parte tanto del lenguaje cotidiano como de la literatura especializada en administración, no es mucho el consenso sobre lo que los principales términos que aluden a esta gestión significan ni tampoco su relación con la planificación. Se propone en este trabajo un conjunto de conceptos mediante los cuales se plantea que la evaluación es a la planificación estratégica lo que el control es a la operativa $y$, en este encuadre, se identifican algunos conceptos usuales de control y evaluación tales como eficiencia, eficacia y efectividad.

En la primera parte del documento se incluyen algunas precisiones sobre los conceptos de información, control y evaluación y, en especial, las condiciones que deben cumplirse para que las informaciones puedan ser utilizadas para contro-

lar y para evaluar. La segunda parte se refiere a las gestiones institucionales de control y evaluación y a su evolución, desde su origen como prácticas informales, hasta su institucionalización como sistemas formales y, en estos casos, algunas de las características técnicas de los mismos, en particular la diferencia entre sistemas de gestión y los llamados sistemas especializados de información, control y evaluación. Finalmente, el último punto se refiere a la importante cuestión de las relaciones entre el control y la planificación. En particular se tratan algunos aspectos tales como la posibilidad de controlar y evaluar de manera independiente o en ausencia de la planificación y, especialmente, la estrecha relación que existe entre las prácticas de planificación y las de control en los niveles operativos en cuanto ambas se refieren a procesos -es decir, a actividades en las que se usan recursos. 